I. Murat MD, J. Walker MBBs, C. Esteve MD, K. Nahoul PH D, C. Saint-Maurice MD

\title{
Effect of lumbar epidural anaesthesia on plasma cortisol levels in children
}

The cortisol response to surgery was studied in two groups of children one to eight years old during the first 24 hours after lower abdominal or peripheral surgery. The children were randomly allocated to a control ( $C$ ) group $(n=6)$ or an cpidural (E) group $(n=7)$, In Group $C$, surgery was performed under gemeral anaesthesia and postoperaive pain relief was achieved by using non-narcoric analgesics only. In Group E, lumbar epidural anaesthesia was combined with light general anaesthesia and postoperative pain relief was achieved by intermittent doses of bupivacaine administered ihrough an epidural catheter. Corrisol levels were assessed before surgery (C), at the end of surgery $\left(\boldsymbol{H}_{0}\right)$, at the $3 \mathrm{rd}$, 6th, 12 th and 24 th postoperative hours $\left(H_{3}, H_{6}, H_{12}, H_{24}\right)$. In Group $C_{\text {, cortisol levels increased }}$ significantly at $H_{0}, H_{3}$ and $H_{6}$, whereas in Group $E$, a significant decrease was observed at $H_{0}$ and a significant increase at $H_{12}$. Mean cortisol values at $H_{B}$ and $H_{24}$ were significantly lower in Group $E$, when contared with those measured in Group $C$. In Group $E$, all postoperative cortisol values remained within the normal range, despite the low level of sensory blockade achieved. This suggests that minimal doses of epidural bupivacaine are effective in decreasing the endacrine stress response to surgery in children. This could be of clinical relevance in high-risk children with poor nutritional status. In Group $C$, the cortisol response remained altered for a longer period of time.

\section{Key words}

ANAESTHESIA: paediatric; ANAESTHESIA REGIONAL: epidural; STRESS: surgery.

From the Departement D'Anesthesie Reanimation and the Service d'Endocrinologie Pediatrique (J.W.) Hopital Saint Vincent de Paut, Paris France and the Fondation de recherche en Hormonologie (K.N.) Paris, France.

Address correspondence to: Dr. I. Murat, Departement d'Anesthesie Reanimation, Hopital Saint Vincent de Paul, 74 avenue Denfert Rochereau, 75674 Paris Cedex 14 France.
The endocrine stress response to surgery occurs in children as in adults, even after minor surgical procedures. ${ }^{1-3}$ Epidural anaesthesia modifies this response in adults. The decrease in stress response mainly depends on the severity of surgical injury, and on the degree and the extent of the blockade achieved during the surgical procedure $^{4-7}$ To obtain the suppression of the cortisol response after lower abdominal surgery, a block extending from $S_{5}$ to $T_{4}$ is required. ${ }^{R}$

Epidural anaesthesia is now increasingly used in children, especially for surgical procedures of long duration and for painful pracedures. ${ }^{9}$ Postoperative analgesia is provided by intermittent "top-ups" of local anaesthetics using the epidural cathetcr already in place. In children, compared to adults, lower concentrations of local anaesthetics are usually sufficient to provide adequate peroperative analgesia, and postoperative analgesia of longer duration is usually obtained, especially in young children. ${ }^{10}$ No studies are available on the postoperative changes in cortisol response in children. Thus this study was performed to assess the cortisol response in children during the first 24 hours after surgery to the lower part of the body, and the effect of lumbar epidural anaesthesia on this response

\section{Methods}

\section{Patients}

The study was performed in two groups of children, one to eight ycars old (ASA physical status 1). All were scheduled for elective surgical procedure of the lower part of the body: complex hypospadias repair or club foot repair. They were randomly allocated to a control $(C ;$ six children) or an epidural ( $E$; seven children) group. The study was approved by the Ethics Committee of the Hospital and parental consent was obtained during the preoperative visit.

\section{Anaesthesia}

The children were not premedicated. In both groups, induction of anaesthesia was carried out by face mask with halothane plus nitrous oxide and oxygen (50:50). 
Intubation was facilitated using vecuronium and ventilation was controlled throughout the surgery. In the control group, general anaesthesia was maintained using nitrous oxide ( 50 per cent), halothane or enflurane and intermittent intravenous injections of narcotics. In the epidural group, lumbar epidural anaesthesia was performed before the start of surgery using a $18 \mathrm{G}$ or a $20 \mathrm{G}$ Tuohy needle. An epidural catheter ( $20 \mathrm{G}$ or $24 \mathrm{G}$ ) was placed and secured in a low lumbar interspace $\left(\mathrm{L}_{3}-\mathrm{L}_{4}\right)$. All children received an initial injection of $0.75 \mathrm{ml} \cdot \mathrm{kg}^{-1}$ of 0.25 per cent bupivacaine with epinephrine (1:200,000). "Top-up" doses were administered during surgery when changes in blood pressurc or hcart ratc indicated insufficicnt analgesia. One half the initial dose of the same lacal anaesthetic was administered for each "top-up." General anaesthesia was maintained using low inspired concentrations of halothane ( $<0.5$ per cent) or enflurane ( $<1$ per cent). The level of blockade was assessed at the end of the surgical procedure by pinprick. Children in both groups were extubated at the end of surgery. No narcotic antagonists were used in the control group at the end of operation.

\section{Postoperative analgesia}

Children in the control group received non-narcotic analgesics only during the first 24 postoperative hours. In the epidural group, "top-ups" of 0.25 per cent bupivacaine with epinephrine were given by the anaesthetist when clinical manifestations of pain were noted by the nurses or the parents.

\section{Measuremenis}

Six venous blood samples of $3 \mathrm{ml}$ each were collected from a short catheter inserted in an antecubital vein, to assess the cortisol levels. Samples were kept at $4^{\circ} \mathrm{C}$ and then the plasma was separated and frozen for srorage until the cortisol levels were determined. Plasma cortisol levels werc assayed by a specific radioimmunoassay, as previously described. ${ }^{11}$ Control values (C) were obtained after induction of general anaesthesia but before skin incision and before epidural anaesthesia. All were collected between 0800 and 1000 hours. Four postoperative samples

TABLE I Patient characteristics (mean \pm SD)

\begin{tabular}{llll}
\hline & $\begin{array}{l}\text { Control group } \\
n=6\end{array}$ & $\begin{array}{l}\text { Epidural group } \\
n=7\end{array}$ & $p$ \\
\hline Agc & 46 & 40.3 & ns \\
months & \pm 28.2 & \pm 26.7 & \\
Weight & 14.2 & 15.5 & ns \\
kg & \pm 5.5 & \pm 6.5 & \\
Surgery & 151 & 127 & ns \\
min & \pm 67 & \pm 30 & \\
\hline
\end{tabular}

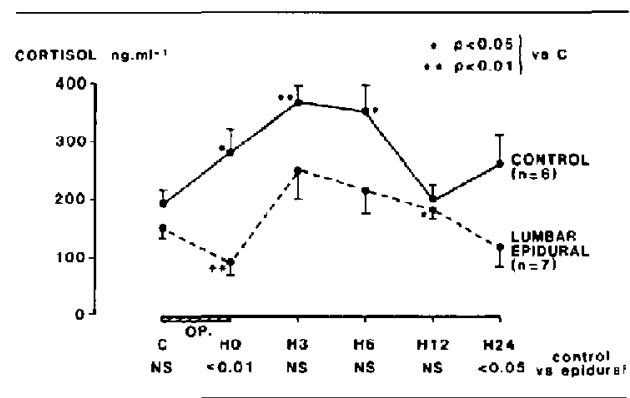

FIGURE Plasma cortisol levels (mean \pm SEM) . C: control values before surgery. $\mathrm{H}_{0}$ i end of surgery. $\mathrm{II}_{3}, \mathrm{H}_{6}, \mathrm{H}_{12}, \mathrm{H}_{24}$ : $3 \mathrm{rd}$, 6th, 12th and $24 \mathrm{~h}$ postoperutive hours. Stars indicate significant changes within a group compared with control yalues $\left(^{*} p<0.05_{*}^{* *} p<0.01\right.$ ). Significant changes between groups are indicated at the bottom of the figure.

were collected at the following times: at the end of surgical procedure $\left(\mathrm{H}_{0}\right)$, at the $3 \mathrm{rd}\left(\mathrm{H}_{3}\right), 6$ th $\left(\mathrm{H}_{6}\right)$, and 12th $\left(\mathrm{H}_{12}\right)$ postoperative hours. The last sample was collected the day after surgery between 8 and 10 A.M., i.e., between the 20 th and the 24 th postoperative hour $\left(\mathrm{H}_{24}\right)$.

\section{Statistical analysis}

Statistical analysis was performed using two-way analysis of variance, and then, when appropriate, the paired Student's t test and the unpaired Student's $t$ test to compare data within a group and between the groups. The null hypothesis was rejected when $\mathrm{p}$ values were $<0.05$.

\section{Results}

The two groups of children were similar with respect to weight, age and duration of surgical procedure (Table I). Cortisol control values were also similar in the two groups. All the control values, except one, were within the normal ranges of our laboratory for children of this age group ( $50-250 \mathrm{ng} \cdot \mathrm{ml}^{-1}$ ). Analysis of variance revealed significant differences in cortisol values between groups ( $p<0.5$ ) and within the groups $(p<0.02$ in the control group; $p<0.05$ in the epidural group). Results are shown in Table II and the Figure. In the control group, cortisol levels increased significantly at $\mathrm{H}_{0}, \mathrm{H}_{3}$ and $\mathrm{H}_{6}$, compared with control values. In the epidural group, cortisol values decreased significantly at the end of surgery $\left(\mathrm{H}_{0}\right)$, whereas a significant increase was observed at $\mathbf{H}_{12}$. Mean values measured in the epidural group were significantly lower than those of the control group ( $\mathrm{p}<0.05$ ). Statistical significance between groups was reached at $\mathbf{H}_{0}$ and $\mathrm{H}_{24}$. All postoperative cortisol values in the contro] group remained within the normal ranges for our laboratory. 
TABLE II Plasma cortisal levels $\mathrm{ng} \cdot \mathrm{ml}^{-1}$ (mean \pm SEM)

\begin{tabular}{lllllll}
\hline & $\mathrm{C}$ & $H_{0}$ & $H_{3}$ & $H_{0}$ & $H_{12}$ & $H_{24}$ \\
\hline Control group & 193 & 281 & 367 & 349 & 201 & 262 \\
(C) & \pm 20 & \pm 40 & \pm 31 & \pm 48 & \pm 26 & \pm 53 \\
& & $*$ & $\dagger$ & $*$ & & \\
Epidural group & 149 & 91 & 251 & 216 & 183 & 122 \\
(E) & \pm 18 & \pm 27 & \pm 46 & \pm 41 & \pm 17 & \pm 36 \\
& & $\dagger$ & & & $*$ & \\
Evs C & ns & $<0.01$ & ns & ns & ns & $<0.05$ \\
\hline
\end{tabular}

${ }^{*} \mathrm{p}<0.05$ versus control values.

tp $<0.01$ versus control values.

C: control values before surgery.

$\mathrm{H}_{0}$ : end of surgery.

$\mathrm{H}_{3}, \mathrm{H}_{6}, \mathrm{H}_{12}, \mathrm{H}_{24}: 3 \mathrm{rd}$, 6th, 12th and 24th postoperative hours.

In the epidural group, complete analgesia was obtained during surgery and no narcotics were used. The upper level of sensory blockade ranged between $T_{6}$ and $T_{10}$ at the end of the surgical procedure. Between 0 and 3 "top-up" doses of bupivacaine were administered during the first 24 postoperative hours ( 3 in 1,2 in 1,1 in 4 , and 0 in 1). In the six children who required postoperative bupivacaine administration, the time of the first "top-up" ranged between the 2 nd and the 23 rd postoperative hour (mean 8.5 hours). The maximum sensory level achieved after each "top-up" was always lower than $\mathrm{T}_{10}$ -

\section{Discussion}

The recent interest in developing regional anaesthesia techniques in children is mainly related to their ability in providing adequate pain relief. The use of epidural anaesthesia for long surgical procedures in children allows reduced use of muscle relaxants and avoidance of narcotics, and therefore decreases the risk of postoperative respiratory depression. The development of this technique has been long limited by the lack of special equipment, cspecially for small children. Although the major goal of epidural anaesthesia is to provide pain relief, the efficacy of this technique in children remains to be assessed.

The decrease in the endocrine stress response to surgery observed after epidural anaesthesia is mainly related to blockade of afferent neurogenic impulses from the site of surgery. However, discussed below, only a decrease in the endocrine stress response to surgery can be considered as a reliable criterion of complete sensory blockade, since there is not perfect correlation between effective clinical analgesia and the intensity of neural blockade. The benefit of reducing the stress response remains controversial; however, the postoperative cortisol increase may contribute to a decrease in postoperative glucose tolerance. Therefore one can expect a beneficial effect of this technique in high-risk children with poor nutritional status.

In the control group, the expected increase in cortisol values was observed at the end of the surgical procedure. A similar increase has been described in children, but not in neonates, after various surgical procedures and various techniques of anaesthesia. ${ }^{1-3}$ Adequate premedication can decrease the peroperative rise in cortisol, but it does not suppress the significant increase observed at the end of surgery. ${ }^{3}$ In none of these studies were samples collected following surgery.

In adults, there is a circadian rhythm of steroid secretion in which plasma cortisol levels rise several hours after initiation of sleep, peak shortly after waking, and then fall during the morning. ${ }^{12}$ This circadian rhythm can be altered by various stresses, including acute or chronic pain. ${ }^{13}$ Although this circadian rbythm is not present until between three and eight years of age, ${ }^{14}$ the mean cortisol values during the first six postoperative hours observed in our study were significantly increased compared with control values, and were all above the maximum normal levels $\left(50-250 \mathrm{ng} \cdot \mathrm{ml}^{-1}\right)$. No attempt was made in this group to obtain complete pain relief in the postoperative period, but no manifestations of excessive or untolerable pain were noted. In adults, a progressive increase in cortisol levcls was also reported during the first six hours after surgery. ${ }^{8}$

In the epidural group, a significant decrease in cortisol levels was observed at the end of surgery. This decrease suggests that adequate analgesia was obtained, and that afferent neurogenic impulses from the site of surgery were adequately blocked throughout the surgery. Our results differ from those reported by Engquist et al. in adults ${ }^{8}$ where suppression of the cortisol response was only obtained using 0.5 per cent bupivacaine with a block extending from $T_{4}$ to $S_{5}$. Although the exact level of blockade could not be assessed during surgery in our study, it seems unlikely that a block as high as $T_{5}$ may have been obtained, because minimal stimulation of the upper part of the body usually produced moving or awakening during surgery, due to the light level of generul anaesthesia used.

The surgical procedures involved in our study mainly affected the flow of impulses from the sacral and lower lumbar roots. The large diameter of these roots explains why high concentrations of bupivacaine are usually required to achieve a complete blockade in adults. In children, however, no failure of blockade of sacral roots has heen observed after a lumbar epidural injection. ${ }^{9}$ This may be attributed to the lesser extent of the myelin sheath and the smaller diameter of nerve fibres in children compared with adults, allowing the local anaesthetics to more easily reach the nerve membrane. 
Throughout the study all cortisol values remained at a significantly lower level in the epidural group than in the control group. Mean values of the epidural group remained within the physiological range. Adequate analgesia was obtained in the epidural group as subjectively assessed by the nursing staff and the parents. No pain scales were used in the postoperative period, because most of the children were too young. The need for postopcrative "top-up" doses varied between children, despite the similarity in procedures and levels of analgesia at the end of surgery. The low doses of local anaesthetic used during the postoperative course suggest that all the afferent pain pathways could not have bcen fully blocked during this time. A recent study ${ }^{15}$ demonstrated a lack of correlation between clinical analgesia obtained after lumbar epidural injection of bupivacaine in adults and the corresponding decrease of the amplitude of somatosensory evoked potentials. This suggests that a partial blockade can provide sufficient postoperative analgesia.

The day after surgery, cortisol values were all within the normal range in the epidural group, whereas they remained at a significantly higher level in the control group. This suggests that the stress response can persist even after 24 hours followed lower abdominal or peripheral surgery and that epidural anaesthesia can reduce this response. This effect could be beneficial in high-risk children, especially in those with poor nutritional status.

In conclusion, this study demonstrates that cpidural anaesthesia is effective in reducing the cortisol response to surgery in children. However, compared to adults, lower concentrations of bupivacaine as well as a lesser extent of neural blockade appear to be sufficient to provide both complete and prolonged analgesia and a reduction of cortisol response. This difference is probably related to anatomical differences between children and adults. This suggests that the use of low concentrations of bupivacaine ( 0.25 per cent) is a reasonable choice in young children for perioperative analgesia.

\section{References}

1 Obara $H$, Sugiyama $D$, Maekawa $N$ et al. Plasma cortisol levels in paediatric anaesthesia. Can Anaesth Soc J $1984 ; 31: 24-7$.

2 Sigurdsson GH, Lindahl SGE, Narden N. Catecholamine and endocrinc responses in children during halothane and enfurane anaesthesia for adenoidectomy. Acta Anaesthesiol Scand 1984; 28: 47-51.

3 Lindahl SGE, Charlton AJ, Hatch DJ, Norden NE. Endocrine response to surgery in children after premedication with midazolam or papaveretum. Eur J Anesthesiol 1985; 2: $369-77$.
4 Lush D, Thorpe JN, Richardson DJ, Bowen DJ. The effect of epidural analgesia on the adrenocortical response to surgery. Br J Anaesth 1972; 44: 1169-72.

5 Gordon NH, Scott DB, Percy Robb JW. Modification of plasma corticosteroid concentrations during and after surgery by epidural blockade. Br Med J 1973; 1: 581-3.

6 Cooper GM, Holdcroft A, Hall GM, Alaghband-Zadeh J. Epidural analgesia and the metabolic response to surgery. Can Anaesth Soc J 1979; 26: 381-5.

7 Kehlet H. Brandt MR. Prange-Hansen A. Alberti KGMM. Effect of epidural analgesin on metabolic profiles during and aftcr surgery. Br J Surg 1979; 66: 543-6.

8 Engquist A, Brandt MR, Fernandes A, Kehtet $H$. The blocking effect of epidural analgesia on the adrenocortical and hyperglycemic responses to surgery. Acta Anaesthesiol Scand 1977; 21: 330-5.

9 Mural I, Dellew MM, Esteve C, Egu JF, Saint-Maurice $C$. Continuous epidural anaesthesia in children. Clinical and haemodynamic implications. Br I Anaesth 1987 (in press).

10 Warner MA, Kunkel SE, Dawson B, Archinson SR. The effects of age and the addition of epinephrine to bupivacaine for caudal analgesia in pediatric patients. Anesthesiology 1985; 63: A464.

11 Nahout K, Daffos F, Forestier F, Scholler R. Cortisol, cortisone, and dehydroepiandrosterone sulfate levels in umbilical cord and marernal plasma between 21 and 30 weeks of pregnancy. J Steroid Biochem 1985; 23: 445-50.

12 Katz FH, Romfh P. Smith JA. Diurnal variation of plasma aldosterone, cortisol and renin activity in supine mank. J Clin Endocrinol Metab 1975; 40: 125-34.

13 Domzal T, Szczudlik A. Kwasucki J, Zaleska B, Lypka A Plasma cortisol concentrations in patients with different circadian pain rhythm. Pain 1983; 17: 67-70.

14 The adrenal cortex. in: Endocrinology and metabolism. Felig P, Baxter JD, Broadus AE, Frohman LA (cds). McGraw-Hill Book Company New-York 1981 pp 394-403.

15 Lund C, Selmar P, Hansen OB, Hjoriso NC, Kehlet $H$. Effect of epidural bupivacaine on somatosensory evoked potentials after dermatomal stimulation. Anesth Aлalg 1987; 66: 34-8. 
Résumé

Les modifications de la cortisolémie pendant les 24 premières heures postoperatoires aprèn chirurgie abdominale basse ou chirurgie orthopédique ont été étudiées chez deux groupes d'enfants agés de un a huit ans. Le tirage au sort a permis de separer les enfants en deux groupes. Les enfants du groupe "controle" (groupe $C ; n=6$ ) ont été operés sous anesthésie generale. Dans ce groupe, lanalgesie postoperatoire a été realisée par administration d' analgesiques non morphiniques. Chez les enfants du groupe $E(n=7)$, une anesthésie peridurale lombaire a été combinée a une anesshésie generate légere. $L$ 'analgesie postoperatoire a consisté en des reinjections de bupivacaine 0.25 pour cent par le catheter epidural laisse en place d la fin de l' intervention. Les taux plasmatiques de cortisol ont été mesures dans ler deux groupes avant le debut de la chirurgie (C), à la fin de l'acte chirurgical ( $\left.H_{0}\right)$, et aux 3 ème, Géme, 12ème et 24ème heures postoperatoires $\left(\mathrm{H}_{3}, \mathrm{H}_{6}, \mathrm{H}_{2}\right.$. $\left.H_{24}\right)$. Dans le groupe $C$, une augmentation significative du cortisol a été abservée à $H_{0}, H_{3}$ et $H_{6}$. Dans le groupe $E$, le cortisol diminue significativement $a \dot{a} H_{0}$ et augmente significativement a $H_{l 2}$. Les valeurs du groupe $E$ sont significativement inferieures a celles da groupe $\mathrm{C}$ à $H_{0}$ et $H_{24}$. Ces résultats suggèrent que dans le groupe $E$ une analgesie complete a été obtenue pendant la periode operatoire matgré l'utilisation de solution de bupivacaine 0.25 pour cent. Dans ce groupe toutes les valeurs de cortisolémies obrenues en postoperatoire etaient dans les limites des valeurs normales, bien que l'extension du bloc sensitif ait êté moderée. Ceci suggère que des doses minimales de bupivacaine permettent de reduire effectivement ia reponse endocrinienre secondaire à un acte chirurgical. Dans le groupe $C$, les taux de cortisol élevés ont été abserves même à la 24 ème heure postoperatoire en utilisant une technique standard d'anesthésie. La diminution de la reponse au stress lors de lemploi d' une anesthésie peridurale peut contribuer à ameliorer la tolerance glucidique postoperasoire, ce qui est important chez l'enfant denutri. 